\title{
On a growth track with startups: how established companies can pursue innovation
}

\section{Rudolf Freytag}

Rudolf Freytag is CEO of Siemens Technology Accelerator $\mathrm{GmbH}$ (rudolf. freytag@siemens.com) in Munich, Germany. He is responsible for commercialization of Siemens technologies via start-up foundation, sale or licensing (www.sta. siemens.com).
() Rudolf Freytag. Published by Emerald Publishing Limited. This article is published under the Creative Commons Attribution (CC BY 4.0) licence. Anyone may reproduce, distribute, translate and create derivative works of this article (for both commercial and non-commercial purposes), subject to full attribution to the original publication and authors. The full terms of this licence may be seen at http:// creativecommons.org/licences/ by/4.0/legalcode
$\Lambda$ part from traditional approaches to innovation and growth, many large established businesses undertake collaborations with startups as an important tool for exploring emerging markets and advancing the digital transformation of their core business.[1] A critical question that has been neglected by the business literature is: how can this collaboration systematically yield innovative growth for the bigger partner - in a significant magnitude, within the usual planning periods of just a few years and within manageable limits for capital investment and risk?[2]

Taking only a financial perspective, investing in startups would not seem to be a promising growth strategy for large firms. To illustrate why, take the example of newly founded company that achieves its "start of sales" after just one year and generates a million US dollars in revenue after only two years. If revenues then will more than double every year at a 133 percent annual growth rate after that, it will take until year ten for the company to reach 100 million dollars in revenue - a very ambitious projection that only a miniscule fraction of startups achieve.

As this example shows, for established companies with revenue in the multiple hundreds of millions or even several billion, the maximum direct contribution to revenue that a startup can make - even if it is unusually successful - is far too little for a conventional growth strategy, given the usual planning time frame of two to three years.

\section{A growth-through-learning strategy}

My experience at a large corporation working with startups offers some practical guidance on how established companies can develop and implement innovative growth-throughlearning strategies in a highly systematic way when they collaborate with startups.

\section{Startups are not just small versions of big players}

It's crucial that established companies that collaborate with startups have a clear understanding of the ways in which these young firms differ from them. Those differences are precisely what make collaboration valuable.

For example, because of their large existing business, big players in an industry generally operate in a "plan and execute" mode. Startups function in an "explore and adapt" mode. Exhibit 1 schematically shows the strategic aspects of a startup's development.[3] 


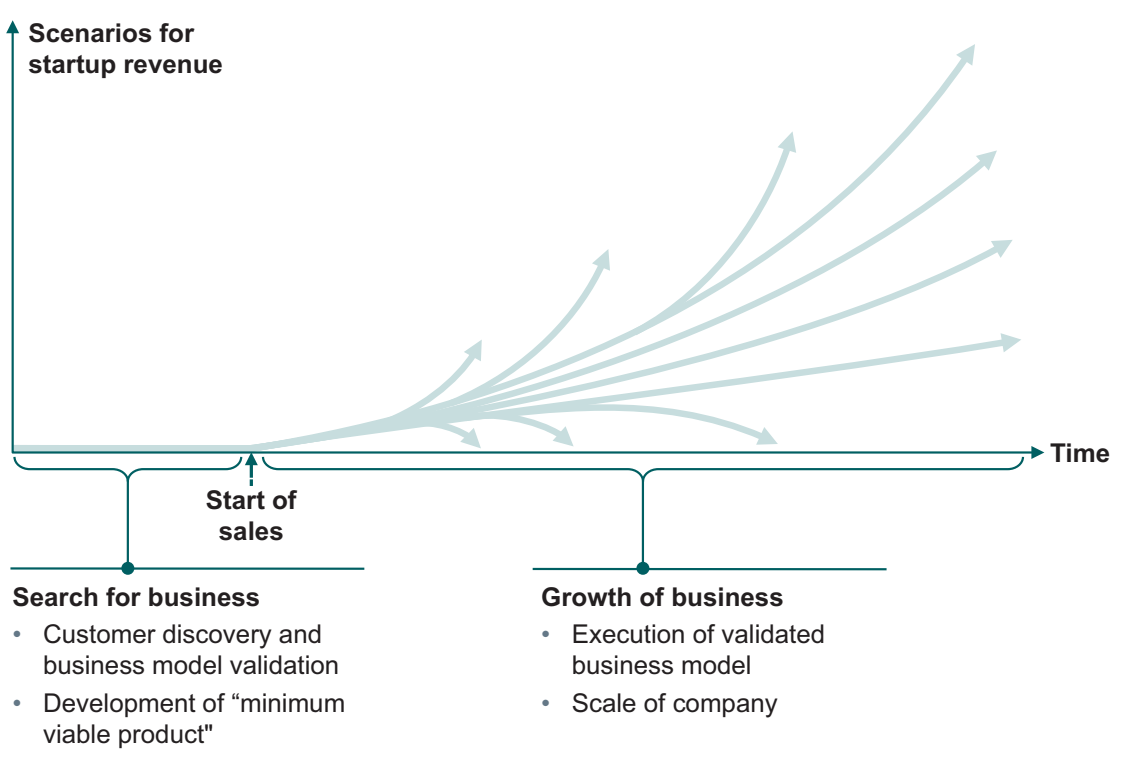

Operating in this explore and adapt mode, newly founded companies go through two main phases in their development. In the "search for business" phase, the startup works on making its business idea a reality in fast, iterative "build-measure-learn" cycles - identifying the right customers and their needs and validating the hypotheses behind the business idea with prototypes so that the first marketable "minimum viable product" can be developed as fast as possible. This may result in significant changes in the original business idea, even to the point of a complete "pivot" away from it to something else. Only with the "start of sales" does the second phase begin - the "growth of business" - in which the previously validated business model is implemented and the startup aims to scale up its revenue as fast as possible. Here again there may be extensive changes in the business model, depending on what the startup experiences in the market.

Startups are a long-shot bet. This is why large companies need to assess risk, time and contribution to growth with the right mindset when working with startups.

\section{There needs to be a leverage effect}

A startup can become relevant to an established company's revenue within a few years only through the "leverage" effect. Collaboration between the established company and the startup must cause an additional stimulation of revenue in the large partner's core business well beyond the small partner's financial contribution.

\section{Case study: The Siemens Digital Factory}

A vivid example of how startups can contribute to innovation, growth and the digital transformation is the further development of Siemens' highly successful Automation Technology business into its "Digital Factory" business, which today holds a global lead in digitalization for industry, with revenue of more than twelve billion euros. [4]

In 2015, the officers at Siemens Automation Technology faced a major strategic inflection point: the core business in automating production lines for the automotive industry, production facilities for the chemical and pharmaceutical industry and other industrial plants 


\section{"A critical question that has been neglected by the business literature is: how can collaboration with startups systematically yield innovative growth for the bigger partner?"}

was excellent, and there were a great many ideas about how to expand business further. On the other hand, it was already clearly evident that digitalization would grow more and more important in industry. Demand for the ability to simulate industrial processes was growing, and it was obvious that over time digitalization would penetrate into every stage of the value chain.

Yet it was also clear that this necessary digitalization could not be achieved by expanding the existing automation business because the company did not have the experience and skills needed to build up a significant software business. So it chose a "buy and build" approach.

To begin with, in 2006 the company acquired UGS, a U.S. company with revenue of more than a billion US dollars. UGS had developed a software platform that controlled digital management of a product's entire life cycle - development, simulation, testing and operation, all the way to service. In combination with the products already in hand for industrial automation, this made it possible to advance gradually the digitalization of Siemens' Automation Technology business, which was renamed the "Digital Factory." This digitalization has multiple advantages for businesses like automotive manufacturers. It enables them to test vehicles' driving characteristics during the development stage using digital simulation, thus shortening development time and the time to market launch.

Another key aspect of this "buy and build" approach was that further acquisitions in addition to UGS systematically expanded the range of software capabilities. An important role was played by startups like Polarion.[5]

Polarion had created a software platform that was especially efficient in supporting workflows for the development of complex hardware and software products. Siemens hypothesized that Polarion's innovative solution might be very attractive to many customer groups as an addition to Digital Factory's own software platform and that Polarion's software might prove a worthwhile lever for further innovative growth in Digital Factory's existing business. To test that hypothesis, in 2014 it made a cooperation agreement with Polarion that was supplemented with a minority venture capital investment. This cooperative arrangement quickly evolved so well that in 2016, Digital Factory acquired all of Polarion.

\section{The Startup Toolbox for established companies}

Industry leaders can gain systematic access to innovative growth through startups only if they clearly distinguish between two fundamentally different objectives:

- Exploration to develop the growth strategy: Here established companies' goal is to work with startups to detect trends, identify fields for innovative growth, develop hypotheses for growth strategies and then effectively test those hypotheses. These tests are highly important because they can significantly reduce market and technology risk during a subsequent implementation.

- Execution to carry out the growth strategy: At this stage, large partners work with startups to implement the adopted growth strategy in practice and to achieve innovative revenue growth of a relevant magnitude, with acceptable risk. 
Because of their different objectives, exploration and execution differ significantly in their operational configuration:

- In the exploration phase, many small, parallel projects cover a relatively wide search range, enabling collaboration partners to look around broadly in the constellation of startups to find an interesting one. These projects must be flexible, they usually last a few weeks or months. Project continuation depends on achieving milestones, and there are no longer-term commitments involving either content or finances. Each individual project has a relatively high risk, but the flexibility here, combined with the relatively low individual investment for each project, permits appropriate risk management. Consequently exploration via startups is a very efficient tool for deriving and validating an innovative growth strategy.

- Execution is about implementing the validated, adopted growth strategy in just a few larger projects, with a well-defined focus and a project duration of months or years. When much of the implementation risk has been reduced during exploration there can be a longer-term commitment of content and finances both to the startups and to customers and other partners, with the aim of building business.

It may well happen that the startups involved in the exploration phase to develop the growth strategy will then not be the ones participating in the implementation of that growth strategy in the execution phase. That may be the result of advancing knowledge during exploration, or may simply be because a young company's business model changed drastically, and though it was a good fit during exploration it is no longer workable for execution.

The strategic startup toolbox in Exhibit 2 shows the four individual tools - scouting, collaboration, minority investment and majority investment - that established companies may use for exploration and execution with startups:

\section{Scouting}

Startup scouting is an excellent exploration tool for getting an overview of the newcomer scene. This "look into the future" provides valuable indications about new technologies, innovative business models, relevant market participants and the maturity of the various activities concerned.[5]

In the "Siemens Digital Factory" case, continuous worldwide startup scouting is a key instrument for monitoring the market, competition and technology. This scouting is also what caused Digital Factory to cross paths with the young company Polarion, which would subsequently become a major component of its digitalization strategy.

\section{Exhibit 2 Startup Toolbox for established companies}

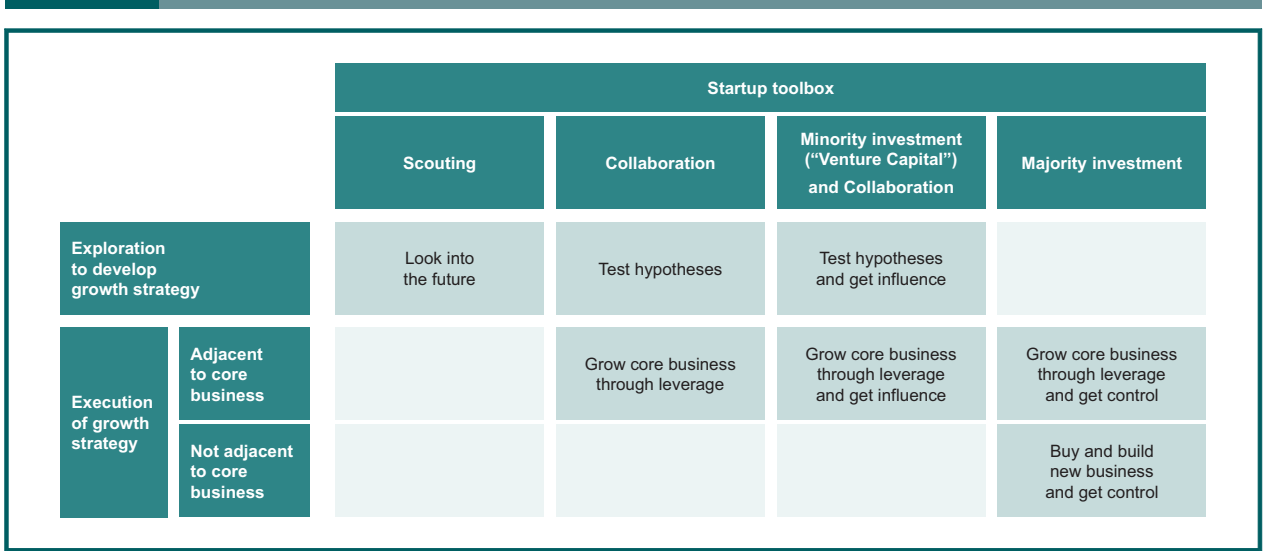


Scouting projects can be conducted quite easily by an established company's own employees. As a supplement, collaboration with networking organizations like Plug-andPlay, Munich Network and other, that view themselves as platforms for linking startup communities with the world of larger partners, has also proved quite useful.[6] The economies of scale of these networking organizations, with their many thousands of contacts, go far beyond what an individual established company could set up and maintain on its own. Moreover, these organizations offer an opportunity for big players to exchange experiences with one another, which is especially helpful for firms that are just beginning to get involved with collaborating with startups.

\section{Collaboration}

Collaboration includes any form of activity between established companies and startups. In the sample case of Siemens Digital Factory, collaboration with the Polarion startup began in order to find out how well Polarion's software solution would fit with Digital Factory's existing offerings. For Polarion, these were the first steps toward gaining Siemens as a customer and selling its own software through Siemens' sales channels. The project also gave Siemens a concrete example that yielded important insights into the market and the technology of requirement management systems and their attractions as part of a complete Siemens solution.

As the example shows, established companies have a strategic interest in collaborating with startups so as to become familiar with new products, markets, technologies and business models and also to develop hypotheses for growth strategies and test those hypotheses. Startups, for their part, also have an interest in collaborating with big, strong partners because that gives them access to customers, technologies and production capacity to build up their own business fast - access that is not accessible without such a cooperation arrangement. This offers an excellent basis for designing the collaboration projects as genuine win-win partnerships.[7]

Collaboration projects are highly flexible instruments in which all rights and obligations can be clearly defined. These include such matters as the work to be performed, milestones and financing and the question of rights to the project's results. This last becomes especially important if, for instance, the two sides develop prototypes jointly, conduct joint market tests or file for patents together.

In the exploration phase, collaboration projects can be used as a flexible tool to test hypotheses for developing growth strategies.

Alternatively, in the execution phase collaboration projects can be used to implement the growth strategy. In such cases, the approach is usually to "grow the core business through leverage." Such projects are generally set up for a longer term and from the established company's viewpoint are aimed at making use of the startup's products or skills to significantly stimulate revenue from the core business by applying the leverage effect just

"Established companies have a strategic interest in collaborating with startups so as to become familiar with new products, markets, technologies and business models and also to develop hypotheses for growth strategies and test those hypotheses." 


\section{"The Strategic Startup toolbox shows the four individual tools - scouting, collaboration, minority investment and majority investment - that established companies may use for exploration and execution with startups."}

mentioned. But to do that, the growth field must be "adjacent to the core business." For that reason, collaboration is also not well suited for growth in activities not adjacent to the core business.

The Siemens Digital Factory case study shows this quite strikingly with the example of the Polarion startup. Siemens' actual core business in classic automation was too far away from the Polarion application for a leverage effect to work; however, the newly acquired software expert UGS is extremely well suited for the purpose.

\section{Minority investments - "venture capital investments" - and collaboration}

Established companies frequently combine collaboration with startups with a minority investment, usually less than 25 percent - a "venture capital investment."[8] Established companies may have various reasons to act as a venture capital investor. It will give them a greater influence over the startup's strategy. They may be able to keep a direct competitor from partnering with the young company or buying it up. And because of the share in the startup they already own, they are assured of a purchase price advantage in the event of a later complete acquisition of the startup if the newcomer's value has risen sharply in the meantime.

It is important for an established company to carefully weigh the advantages and disadvantages of a venture capital investment in addition to a collaboration. An established company has a strategic interest behind its investment and this may bring it into significant conflicts with the interests of the startup's other shareholders, who are pure "financial" investors and are interested only in maximizing the value from the sale of the startup.

\section{Majority investments}

In contrast to a venture capital/minority investment, majority investments yield not just an influence on the investee, but control over it. Because of this responsibility and the generally longer-term commitment involved, majority investments are suited only for the execution phase and not for flexible, time-limited exploration activities.

For startups that were originally financed by venture capital investors, a majority acquisition by an established company means an exit - in other words, a payoff of the risk-capital providers and thus, as a rule, a complete takeover.

An established company's growth strategy adjacent to the core business exists when a majority investment in a startup is intended to serve as a lever to stimulate revenue in the established company's core business.

An established company pursues a growth strategy not adjacent to the core business when it wants to build up a new business that differs so much from its core business that the skills, customers and processes of the core business cannot be used. In that case, for the time being there will not be a possibility of using the leverage effect of startups to build up the new business. But alternatives exist: 
- A "string of pearls" strategy is an attempt to form a new portion of the company by linking and merging smaller companies together. But this method is very rarely a success, because it is expensive and risky to integrate many smaller entities.

- A "buy and build" approach has a better chance of success. Here, a larger company is acquired first to serve as the core for the new business to be formed. Startups are then accumulated around this nucleus, and their leverage effect stimulates its business. If it becomes possible over time to combine the business of the nucleus with the original core business, the "buy and build" approach has achieved its full effect.

That was exactly the case with the Siemens Digital Factory. The new digital business in software that was to be built up was too different from the existing business in industrial automation. The acquisition of the software firm UGS provided the requisite large nucleus for the new business and the subsequent acquisitions of startups like Polarion joined on around it had a leverage effect that stimulated attractive growth in the nucleus. It was also gradually possible to combine the existing automation business and the software business in such a way that the two together are now a mainstay of Siemens' business, as the "Digital Factory."

\section{Developing strategies with the Startup Toolbox}

The strategic Startup Toolbox is a time-tested approach that enables established companies to make systematic use of collaboration with young companies in order to develop and implement an innovative growth strategy and thus generate growth in suitable fields of innovation, with a relevant magnitude and with acceptable risk.

The clear separation between execution and exploration phases makes it possible to select the best startup tool for each case, or to combine various tools in appropriate ways. These startup tools can also easily be linked with the classic tools of business development. These include such techniques as market and trend analyses, research and development both inhouse and with partners, endogenous growth by internationalizing and building market share and exogenous growth through joint ventures or classic mergers and acquisitions (M\&A).

Thus working with startups becomes an important component of innovative growth for established companies in a constantly accelerating market. And as the case study has shown it can also be a way for a company to successfully gain a lead in the digital transformation in its own sector.

\section{Notes}

1. Chang, S.J. (2004), "Venture capital financing, strategic alliances and the initial public offerings of Internet startups," Journal of Business Venturing, 19(5), pp. 721-741, https://doi.org/10.1016/j. jbusvent.2003.03.002. Gutmann, T. (2018), "Harmonizing corporate venturing modes: an integrative review and research agenda," Management Review Quarterly (2018), https://doi.org/ 10.1007/s11301-018-0148-4. Narayanan, V.K., Yang, Y. and Zahra, S.A. (2009), "Corporate venturing and value creation: a review and proposed framework," Research Policy, 38(1), pp. 58-76, https://doi.org/10.1016/j.respol.2008.08.015.

2. Dodgson, M., Gann, D.M. and Phillips, N. (2014) The Oxford Handbook of Innovation Management, Oxford University Press, Oxford, UK. Christensen, C.M. and Raynor, M.E. (2003), The Innovator's Solution: Creating and Sustaining Successful Growth, Harvard Business School Press, Boston, MA.

3. Ries, E. (2011), The Lean Startup, Random House, Inc., New York. Blank, S. and Dorf, B. (2012), The Startup Owner's Manual, K\&S Ranch Inc., Pescadero, CA.

4. Collis, D.J. and Junker, T. (2017), Digitalization at Siemens, Harvard Business School Case 9-717428, Harvard Business School Publishing, Boston, MA. 
5. Freytag, R. and Schewe, G. (2016), "Start-ups erlauben einen Blick in die Zukunft," Zeitschrift F«hrung + Organisation, 1/2016, pp. 31-33.

6. www. plugandplaytechcenter.com and www.munichnetwork.com (accessed 15 May 2019).

7. Freytag, R. (2019), "Strategic negotiations: three essentials for successful partnerships with startups," Strategy \& Leadership, Vol. 47 No. 1 (2019), pp. 19-25, https://doi.org/10.1108/SL-112018-0115

8. Feld, B. and Mendelson, J. (2011), Venture Deals, Wiley and Sons, Inc., Hoboken, New Jersey.

\section{Corresponding author}

Rudolf Freytag can be contacted at: rudolf.freytag@siemens.com

For instructions on how to order reprints of this article, please visit our website: www.emeraldgrouppublishing.com/licensing/reprints.htm

Or contact us for further details: permissions@emeraldinsight.com 